\title{
The Application of Pressure Coefficient in Judging Normal Pressure Reservoirs Connectivity-A Case Study of LD21-X and KL3-Xoilfield in Bohai Bay
}

\author{
Jianmin Zhu, Chunyuan Shi, Xilin Liu, Gen Qian, Qianping Zhang \\ CNOOC Tianjin Company, Tianjin, China \\ Email: zhujm3@cnooc.com.cn
}

How to cite this paper: Zhu, J.M., Shi, C.Y., Liu, X.L., Qian, G. and Zhang, Q.P. (2019) The Application of Pressure Coefficient in Judging Normal Pressure Reservoirs Connectivity-A Case Study of LD21-X and KL3-Xoilfield in Bohai Bay. Open Journal of Geology, 9, 295-305.

https://doi.org/10.4236/ojg.2019.96020

Received: April 4, 2019

Accepted: June 23, 2019

Published: June 26, 2019

Copyright $\odot 2019$ by author(s) and Scientific Research Publishing Inc. This work is licensed under the Creative Commons Attribution International License (CC BY 4.0).

http://creativecommons.org/licenses/by/4.0/

\begin{abstract}
Reservoir connectivity is a critical issue in the process of oil-gas exploration and development. According to the theory of fluid mechanics and the achievements of many scholars, a connected reservoir coincides with a unified formation pressure system; there is a linear relationship between formation pressure and depth in normal pressure system reservoir. However, in high-permeability or multi-phase fluid reservoirs, this method has poor applicability and limitations. Through theoretical analysis and formula derivation, a new method for judging the connectivity of normal pressure reservoirs is found, that is, the inverse proportional function relationship between the pressure coefficient and the depth. In this paper, the relationship between the pressure system and the inverse proportional function has been verified. The function of the same pressure system is unique, monotonic, and has unified asymptote and symmetry axis and vice versa. Examples show that the inverse proportional function is more accurate and reliable for judging reservoir connectivity than the linear function.
\end{abstract}

\section{Keywords}

Formation Pressure Data, Inverse Proportional Function,

Reservoir Connectivity, Bohai Oilfield

\section{Introduction}

The study of reservoir connectivity runs through the whole process of oilfield exploration and development. For the high drilling cost of offshore oil field, it is obviously not feasible to verify the reservoir connectivity by the multiple wells. 
Especially, in the exploration and reserve evaluation stage of oil and gas field, there are only one or two exploration wells in each fault block or trap, understanding the connectivity relationship of oil and gas reservoir directly affects the calculation of reserve scale, the deployment of well network. Traditionally, the linear relationship between formation pressure and depth to determine reservoir connectivity has been widely applied [1] [2], but in high permeability reservoirs, the difference of sealing pressure between different pressure systems is small, and in multi-phase fluid reservoirs, the linear relationship of each phase fluid is inconsistent. Therefore, the linear relationship cannot be a key factor in determining reservoir connectivity. In view of the problems, based on theoretical analysis and formula derivation, this paper proposes to use the inverse proportional function relation between pressure coefficient and depth to judge the connectivity of normal pressure reservoir. By using the pressure data analysis of several normal pressure reservoirs in Bohai Sea, it found that the inverse proportional function of the same pressure system not only has consistency and monotonicity, but also uniform asymptote, symmetry axis, and vice versa.

\section{Research Status of Reservoir Connectivity}

The commonly used techniques to analyze reservoir connectivity include slim layer correlation, logging curve feature correlation, reservoir geological modeling technique, and single attribute description technique, etc [3]. Due to the influence of factors such as limited drilling in the sea area, multiple solutions of seismic data and the heterogeneity of reservoir properties, the application of the above methods is limited to a certain extent. A connected reservoir has a unified formation pressure system, and different reservoirs have different pressure systems, and so using the formation pressure to determine that the reservoir connectivity has been widely used in many oilfields [4] [5].

Li chuanliang (2005) elaborated the basic principle for using the linear relation of formation pressure to judge reservoir connectivity: The reduced (equivalent) pressure at any point of the same reservoir is equal, namely the pressure at different depth of a connected reservoir is located in the same straight line, and the value of the pressure conversion to the reference plane is unique [6].

Shaker (2001) proposed to use fluid residual pressure and sealed pressure to quantitatively and semi-quantitatively analyze the connectivity relationship of reservoirs [7] [8]. The fluid residual pressure is the difference between the formation pressure and the regional hydrostatic pressure in the same depth. The sealing pressure is the pressure difference between two sets of reservoirs separated by the mudstone interlayer and represents the sealing capacity of the mudstone interlayer (Figure 1). The fluid residual pressure of the connective reservoir is the same and there is no sealing pressure.

$$
\begin{gathered}
E P=p_{\mathrm{p}}-p_{\mathrm{p}}^{\text {hydro }} \\
S C=p_{\mathrm{p}}^{\mathrm{d}}-p_{\mathrm{p}}^{\mathrm{u}}
\end{gathered}
$$




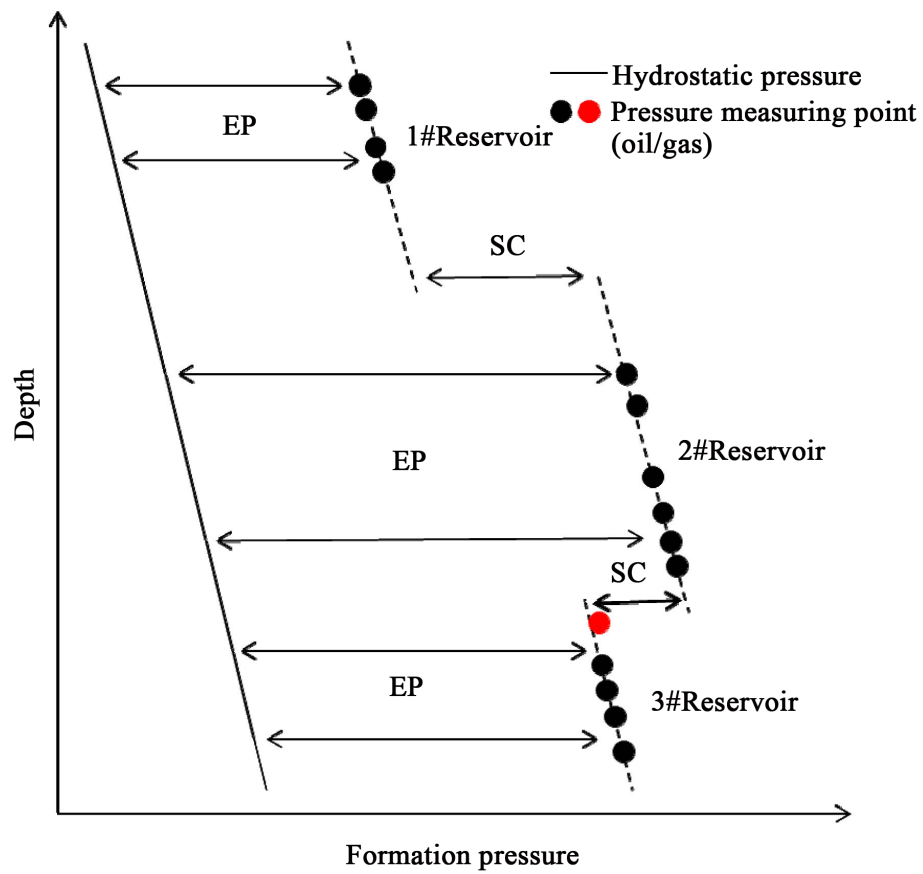

Figure 1. Schematic diagram of reservoir fluid residual pressure and sealing pressure [7] [8].

In this formula: $E P$ is the fluid residual pressure, psi; $S C$ is the sealing pressure, $\mathrm{psi}$; the $p_{\mathrm{p}}^{\mathrm{d}}$ and $p_{\mathrm{p}}^{\mathrm{u}}$ are the formation pressure of overlying and underlying reservoirs of the mudstone interlayer respectively, $\mathrm{psi} ; p_{\mathrm{p}}$ is the original formation pressure, psi; $p_{\mathrm{p}}^{\text {hydro }}$ is hydrostatic pressure, psi.

Due to the high permeability of the reservoir and multi-phase fluid, original formation pressure at the top of the reservoir is "abnormal", the residual pressure of the non-single-phase fluids are different (Figure 1), So there is always an "uncertainty" of the connectivity relationship in practical application. At this time, the linear relationship of the formation pressure and depth cannot be used as the main basis to judge the connectivity relationship of the reservoirs.

On the basis of many scholars' studies, this paper uses rich pressure data from wireline formation tester, uses mathematical formulas to derive, and analyzes thousands of formation pressure data from more than 50 normal pressure hydrocarbon reservoirs in Bohai Bay [9] [10] [11], and puts forward a method to distinguish reservoir connectivity by using the inverse proportional function relation between pressure coefficient and depth, which improves the accuracy of connectivity analysis.

\section{The Inverse Proportion Function Principle}

According to the theory of fluid mechanics, the original formation pressure at any point in a connected normal pressure reservoir meets the pressure equation, that is, the formation pressure and depth of a connected reservoir theoretically present a linear relationship (Figure 2(a)), and the formation pressure increases linearly with the increase of depth [12] [13], as follows: 


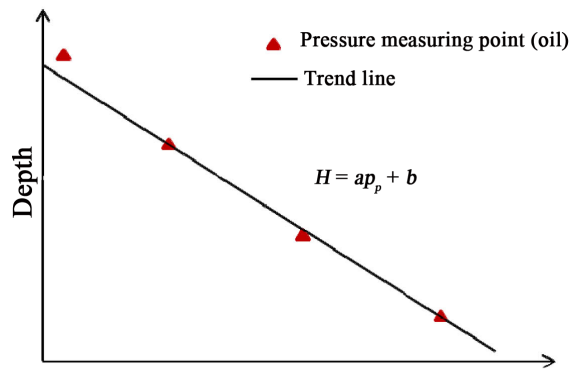

Formation pressure

(a)

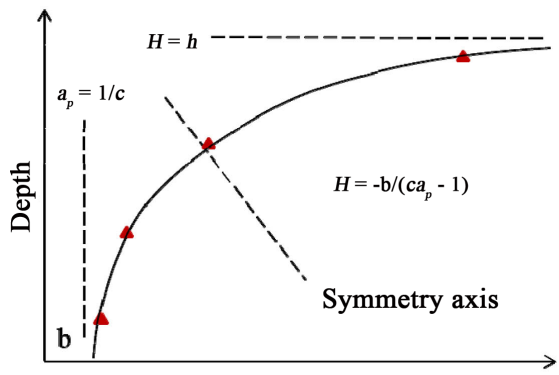

Formation pressure coefficient

(b)

Figure 2. Mathematical model of reservoir pressure and depth. (a) Linear distribution of formation pressure and depth; (b) Distribution of pressure coefficient and depth inversely proportional function.

$$
H=a p_{\mathrm{b}}+b \Rightarrow p_{\mathrm{p}}=(H-b) / a
$$

Another method to study the variation of formation pressure with depth is the pressure coefficient, which is very important but often ignored. Assuming that the formation water density is constant, the following formula is derived:

$$
\begin{gathered}
p_{\mathrm{p}}^{\text {hydro }} \equiv \int_{0}^{h} \rho_{\mathrm{w}}(H) g \mathrm{~d} h \approx \rho_{\mathrm{w}} g H \\
\alpha_{\mathrm{p}}=p_{\mathrm{p}} / p_{\mathrm{p}}^{\text {hydro }}=(H-b) / a \rho_{\mathrm{w}} g H \\
\Rightarrow H=-b /\left(c \alpha_{\mathrm{p}}-1\right)
\end{gathered}
$$

In this formula: $H$ is depth, $\mathrm{m}$; $\rho_{\mathrm{w}}$ is the formation water density, $\mathrm{g} / \mathrm{cm}^{3} ; \alpha_{\mathrm{p}}$ is the pressure coefficient, dimensionless; $a, b, c$ is constant.

The above equation is a variant of the inverse proportional function with pressure coefficient $\alpha_{\mathrm{p}}$ as the independent variable and depth $H$ as the dependent variable (Figure 2(b)), whose original function is $y=1 / x(x>0, y<0)$, which has four basic properties of monotonicity, symmetry, boundedness and consistency [14]. The basic properties of the inverse proportional function are used to analyze the connectivity within the reservoir.

1) The Monotonicity

With the increase of reservoir burial depth, the pressure coefficient shows a monotonic decreasing trend (Figure 2(b)). Influenced by gravity differentiation, fluids of normal pressure reservoir experience differentiation and continuous changes according to density. At higher positions, because of the gas cap or higher crude dissolved gas content, fluid density is smaller, strong compression coefficient (at $20^{\circ} \mathrm{C}$, under the pressure of $6.8 \mathrm{Mpa}$, the isothermal compression coefficient of methane is $1645 \times 10^{-4} \mathrm{Mpa}^{-1}$ ) causes decompression expansion elastic energy to be very huge [15], with the formation pressure higher than the reservoir reduced pressure (Figure $2(\mathrm{a})$ ). In oil-water transitional zone, with the increase of water saturation, fluid density approaches formation water density, formation pressure approaches hydrostatic pressure, and pressure coefficient gradually approaches a constant number. The monotonicity of the pressure 
coefficient is the result of the continuous variation of reservoir fluid properties with reservoir depth.

2) The Symmetry

The inverse proportion function image is an axisymmetric graph, and the axis of symmetry is unique. For a connected reservoir, the image of its pressure coefficient and depth has a unique axis of symmetry, and two or more sets of reservoirs with different symmetry axes do not belong to the same pressure system and are not connected.

3) The Boundedness

There are two asymptotes in the inverse proportional function $\left(\alpha_{\mathrm{p}}=1 / \mathrm{c}, \mathrm{H}=\right.$ $h$ ), and the numerical distribution of pressure coefficient and reservoir height in the same reservoir is controlled by two asymptotes, and different reservoirs with inconsistent asymptotes. With the reservoir altitude becomes shallow, the pressure coefficient is monotonically increasing and approaching the fracture pressure at the top of the reservoir, and the upper limit of the altitude is also getting close to the maximum oil column thickness $h$. As the depth increases, the formation pressure gradually tends to hydrostatic pressure, and the lower limit of the pressure coefficient is also getting infinitely close to hydrostatic pressure coefficient 1/c (Figure 2(b)).

4) The Consistency

The formation pressure at each depth of a connected reservoir can only be fitted to an inverse proportional function image, which has a uniform pressure track, and vice versa.

Under the action of gas, oil, water and other reservoir driving forces, the reservoir pressure system maintains a state of dynamic equilibrium, and the pressure coefficient presents an inverse proportional function distribution with the change of depth. Due to differences in reservoir physical properties, fluid properties and height of oil and gas columns in different reservoirs, the pressure equilibrium state will be different, and then the inverse proportion function will also be different. Therefore, the property of the inverse proportion function can be an important basis for judging the connectivity of reservoirs.

\section{Practical Application}

\subsection{Improving the Reliability of Connection Analysis of High Permeability Reservoirs}

The LD21-X oilfield is located in the southern part of the Liaodong Bay, and is located in the central structural belts of southern Liaozhong Sag in the Lower Liaohe Depression of the Bohai Basin. The main hydrocarbon accumulations are the Neogene Guantao Formation IV and V oil groups (Figure 3). The Guantao Formation is braided river sediment; the reservoirs are developed in horizontal direction. It is characterized by extremely high porosity and permeability. The average porosity of core analysis is $38.2 \%$, and the average permeability is 3628 $\mathrm{mD}$. 


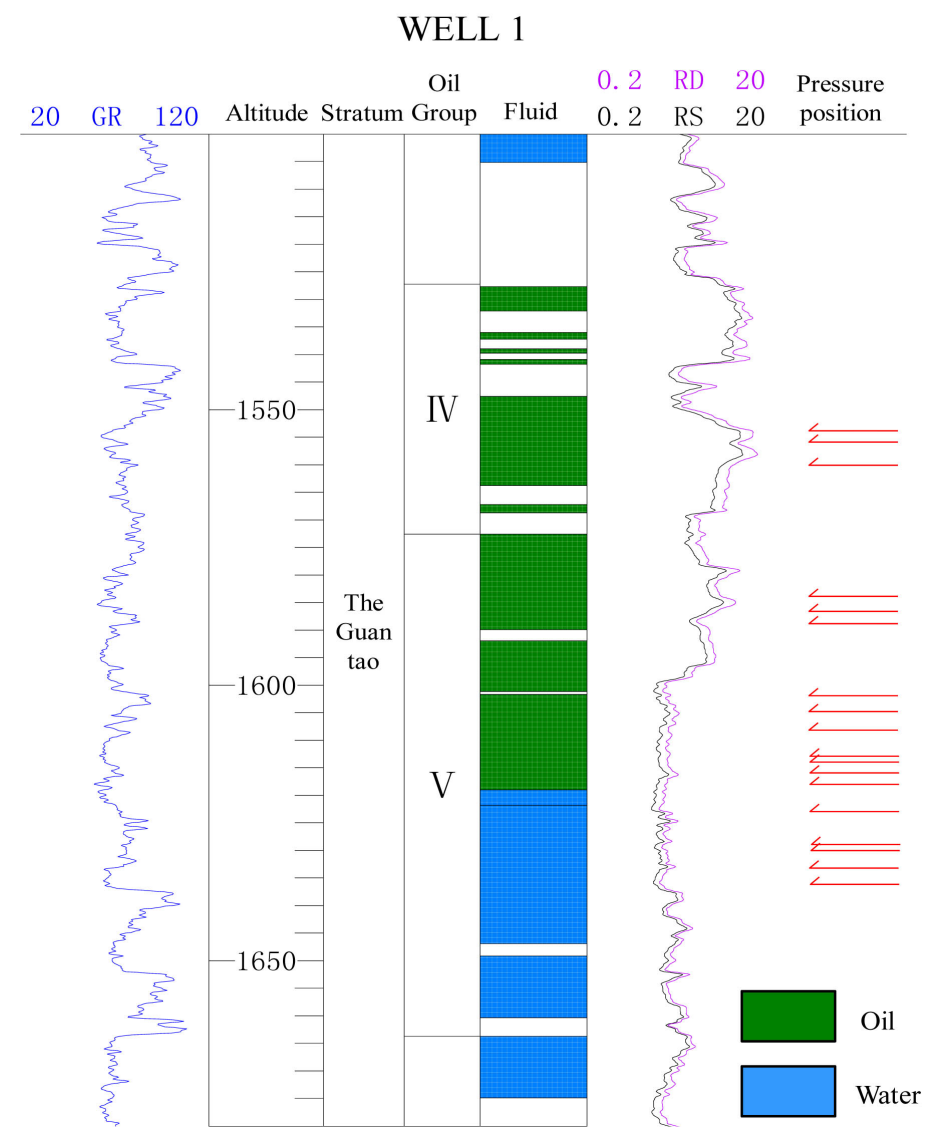

Figure 3. Oil-water distribution and pressure position of the IV and V oil groups of the Guantao Formation of Well 1.

The oil-water contact of the V oil group of Well 1 is $-1619 \mathrm{~m}$. 10 qualified pressure data were obtained from the oil layer of the $\mathrm{V}$ oil group, 5 qualified pressure data were obtained in the water layer, and the measuring depth was in the thicker reservoir section (Figure 3, Table 1). It can be seen from the pressure and depth profile (Figure 4(a)), that the straight line intersection of the oil layer and the water layer of the $\mathrm{V}$ oil group is $-1621 \mathrm{~m}$, equivalent to the actual oil and water contact. From the analysis of pressure coefficient and depth profile, it can be fitted into an inverse proportional function curve (Figure 4(b)). The curve shape belongs to the middle and lower part, which is basically complete. The inverse proportional function is monotonically changing with depth, has two asymptotes and the same axis of symmetry, suggesting that the oil layer and the water layer is a unified pressure systems.

The mudstones of about $3.9 \mathrm{~m}$ thick, is developed between the IV oil group and the $\mathrm{V}$ oil group of Well 1 . The other exploration wells prove that the mudstones are unstable in the oil field, whether the two oil groups are the same fluid system or not need further demonstration. A total of 3 qualified pressure data were obtained from the oil layer of the IV oil group, and the measuring depth was within the thicker reservoir section (Figure 3, Table 1). It can be seen from the pressure and depth profile (Figure 4(a)) that the straight line difference 


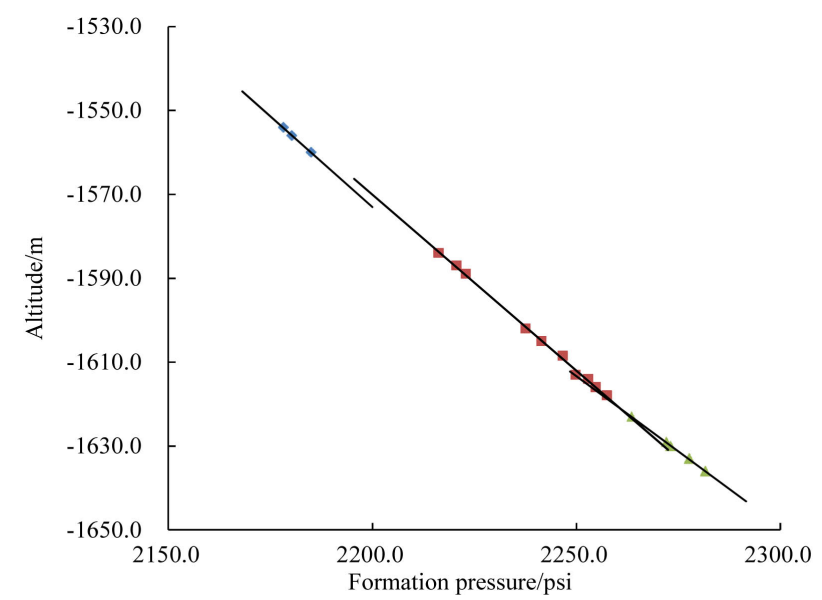

(a)

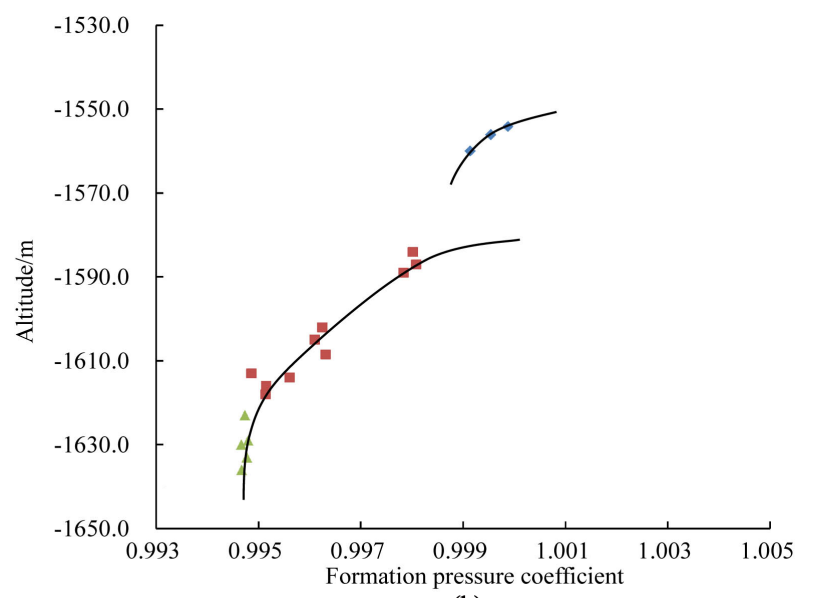

(b)

Figure 4. Pressure/pressure coefficient-depth profile of the IV and V oil groups of the Guantao Formation of Well 1. (a) Formation pressure and depth linear function distribution; (b) Pressure coefficient and depth inverse proportional function distribution.

Table 1. Formation pressure, pressure coefficient of the IV and V oil groups of the Guantao Formation of Well 1.

\begin{tabular}{ccccc}
\hline \multirow{2}{*}{ Well $\quad$ Oil Group } & Altitude/m & $\begin{array}{c}\text { Formation } \\
\text { pressure/psi }\end{array}$ & $\begin{array}{c}\text { Formation pressure } \\
\text { coefficient }\end{array}$ & Fluid \\
\hline \multirow{2}{*}{ IV } & -1554 & 2178.1 & 0.99988 & oil \\
& -1556 & 2180.2 & 0.99954 & oil \\
& -1560 & 2185 & 0.99913 & oil \\
\hline & -1584 & 2216.2 & 0.99802 & oil \\
& -1587 & 2220.6 & 0.99808 & oil \\
& -1589 & 2222.9 & 0.99784 & oil \\
& -1602 & 2237.5 & 0.99626 & oil \\
& -1605 & 2241.4 & 0.9961 & oil \\
& -1608.5 & 2246.7 & 0.99632 & oil \\
& -1613 & 2249.8 & 0.99487 & oil \\
& -1614 & 2252.9 & 0.99561 & oil \\
& -1616 & 2254.7 & 0.99516 & oil \\
& -1618 & 2257.5 & 0.99514 & oil \\
& -1623 & 2263.5 & 0.99473 & water \\
& -1629 & 2272 & 0.9948 & water \\
& -1630 & 2273.1 & 0.99466 & water \\
& -1633 & 2277.6 & 0.99478 & water \\
& -1636 & 2281.6 & 0.99467 & water \\
\hline & & & &
\end{tabular}

between the oil layer of the IV oil group and the oil layer of the V oil group is not large, and it is impossible to determine whether it is a unified pressure system. However, it can be seen from the pressure coefficient and depth profile (Figure 4(b)) that the IV oil group and the $\mathrm{V}$ oil group fail to fit into an inverse proportional function curve with different curve shapes, asymptotes, and symmetry axes, suggesting that the group is not a unified fluid system, and that the 
IV and $\mathrm{V}$ oil groups are different reservoirs.

According to Darcy's law, the higher the reservoir permeability, the smaller the rate of change of formation pressure will be. Even the unconnected sand bodies are in the same layer or adjacent, the residual pressure value of the fluid will not be very different. The traditional linear relationship discriminates the connectivity of high-permeability reservoirs with high uncertainty and low accuracy. However, the law of pressure coefficient and depth is effectively improved the accuracy of the connection analysis of high permeability reservoirs.

\subsection{Avoiding the Effects of Fluid Heterogeneity}

KL3-X oilfield is located in the southern part of the Bohai Sea, and is located in the southern slope of the Huanghekou Sag. The main hydrocarbon accumulation happens in the lower Minghuazhen Formation of the Neogene [16] (Figure 5), which is a subaqueous distributary channel deposition in shallow water delta. The reservoir shows high porosity and permeability, is highly heterogeneous in lateral direction. The average porosity of $1 \#$ sand body and 2\# sand body is $27.2 \%$, and the average permeability is $1431.1 \mathrm{mD}$.

The Well 3 drilled into $1 \#$ and 2\# sand bodies, met the gas layer and the oil layer respectively, and obtained 3 and 6 qualified pressure data respectively (Figure 5, Table 2). Form the pressure and depth profile analysis (Figure 6(a)), the intersection of the two linear functions fitted by the two sand bodies respectively, or the gas-oil contact is $-1483.0 \mathrm{~m}$. The depth is between the 1\# sand body bottom and the $2 \#$ sand body top, thus, whether the two sand bodies are the same pressure system cannot be determined. However, it can be seen from the pressure coefficient and depth profile analysis (Figure 6(b)) that the $1 \#$ and 2\# sand bodies fit into an inverse proportional function curve with same curve shapes, asymptotes and symmetry axes, suggesting that $1 \#$ and $2 \#$ sand bodies are a unified fluid system, and they are one reservoir.

WELL 3

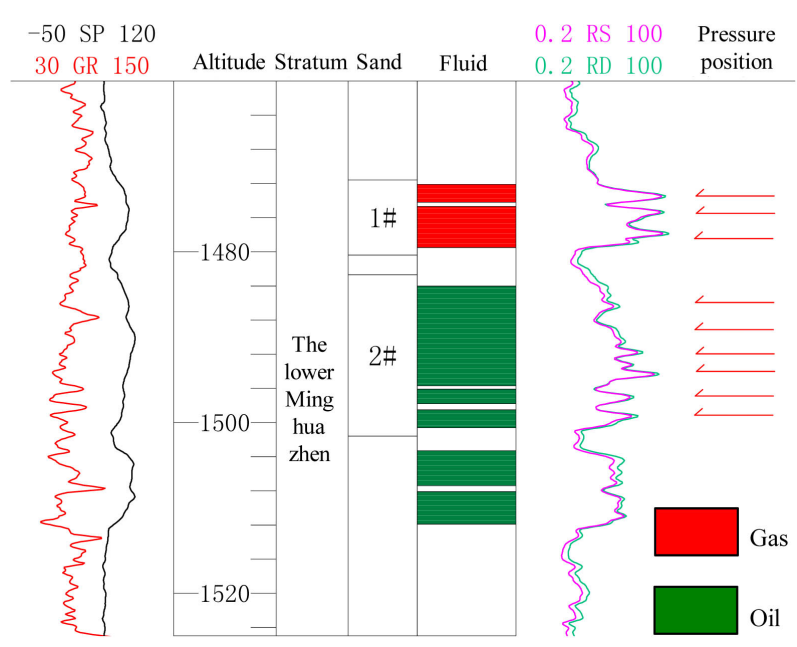

Figure 5. Gas-Oil distribution and pressure position of the 1\# and 2\# Sand of the lower Minghuazhen Formation of Well 3. 


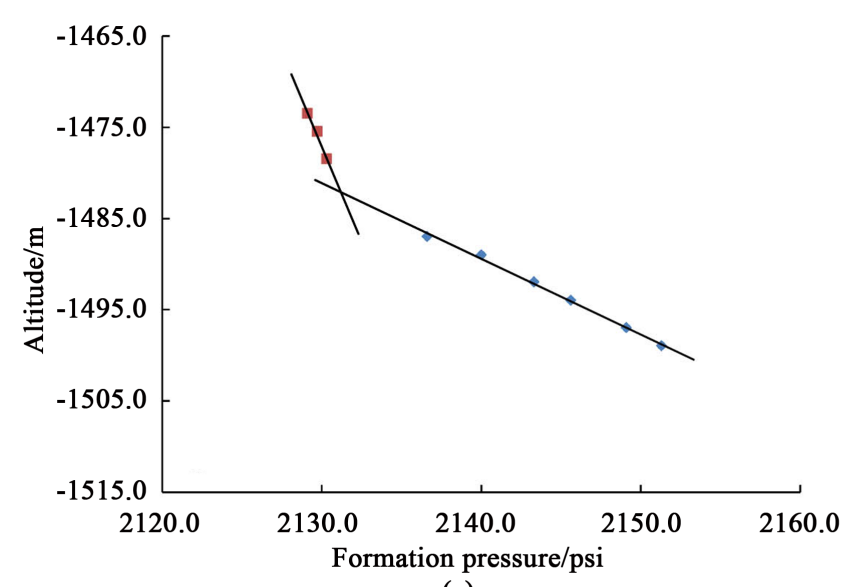

(a)

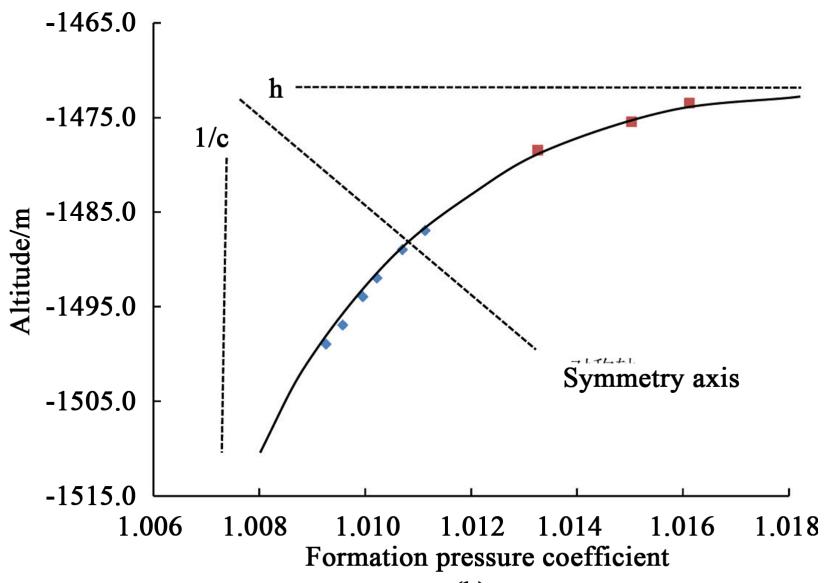

(b)

Figure 6. Pressure/pressure coefficient-depth profile of the 1\# and 2\# Sand of the lower Minghuazhen Formation of Well 3. (a) Stratum pressure and depth linear function distribution; (b) Pressure coefficient and depth inverse proportional function distribution.

Table 2. Formation pressure, pressure coefficient of the 1\# and 2\# Sand of the lower Minghuazhen Formation of Well 3.

\begin{tabular}{|c|c|c|c|c|c|}
\hline Well & Sand & Altitude/m & $\begin{array}{l}\text { Formation } \\
\text { pressure/psi }\end{array}$ & $\begin{array}{c}\text { Formation pressure } \\
\text { coefficient }\end{array}$ & Fluid \\
\hline \multirow{9}{*}{3} & \multirow{3}{*}{$1 \#$} & -1473.5 & 2129.1 & 1.01612 & gas \\
\hline & & -1475.5 & 2129.7 & 1.01503 & gas \\
\hline & & -1478.5 & 2130.3 & 1.01326 & gas \\
\hline & \multirow{6}{*}{$2 \#$} & -1487 & 2136.6 & 1.01112 & oil \\
\hline & & -1489 & 2140 & 1.01069 & oil \\
\hline & & -1492 & 2143.3 & 1.01022 & oil \\
\hline & & -1494 & 2145.6 & 1.00995 & oil \\
\hline & & -1497 & 2149.1 & 1.00957 & oil \\
\hline & & -1499 & 2151.3 & 1.00925 & oil \\
\hline
\end{tabular}

According to the previous research results, the premise of using the formation pressure-depth linear relationship to distinguish the reservoir connectivity relationship is that it has the same fluid properties. Different fluid properties and different linear relationships can cause the connectivity to be inaccurately determined. The pressure coefficient-depth inverse proportional function distribution is generated by the pressure balance of gas, oil, water and other fluids. The function curvature is continuously changed by many factors such as reservoir physical properties, fluid properties and oil column height. The interference of non-single-phase fluid differences on deciding the connectivity of the sand body with the linear relationship is avoided.

\section{Conclusions}

1) Pressure coefficient and depth inverse proportional function are new me- 
thods for analyzing the connectivity of normal pressure oil reservoirs. Consistency of the inverse proportional function, the monotonous changes of pressure coefficient with depth, the same two asymptotes, and symmetry axes are the standards for the connection of sand bodies.

2) Compared with the linear relationship between formation pressure and depth, the pressure coefficient and the depth inverse proportional function method is more sensitive and the result is more reliable.

3) The inverse proportional function curvature of the Bohai Bay normal pressure reservoir is controlled by many factors such as reservoir physical properties, fluid properties and oil column height, which avoids the interference of reservoir high permeability and non-single-phase fluid differences on deciding the connectivity of the sand body with the linear relationship.

\section{Conflicts of Interest}

The authors declare no conflicts of interest regarding the publication of this paper.

\section{References}

[1] Zhao, C.M., Wang, S.P., Liu, W.Y., et al. (2009) Application of FMT Pressure Analysis in Reserves Estimate of Bohai J25-1 Oilfield. Fault-Block Oil and Gas Field, 16, 85-87.

[2] Zoback, M.D. (2007) Reservoir Geomechanics. Cambridge University Press, New York, 3-55.

[3] Liu, C.Q., Lv, D.Y., Hou, D.M., et al. (2008) Study of Connectivity of Sand Bodies in A, Bohai Area. Geophysical Prospecting for Petroleum, 47, 251-255.

[4] Wang, C.X., Cao, W.L. and Wang, X.R. (2008) Pressure Gradient Computation and Application of Wireline Formation Tester. Petroleum Exploration and Development, 35, 476-481. https://doi.org/10.1016/S1876-3804(08)60096-8

[5] Wu, Y.P., Meng, X.M., Hu, S.M., et al. (2015) Reservoir Connectivity and Availability of Dina 2 Gas Field. Natural Gas Exploration and Development, 28, 43-46.

[6] Li, C.L. (2005) Fundamentals of Reservoir Engineering. Petroleum Industry Press, Beijing, 5-7.

[7] Shaker, S.S. (2014) Reservoir vs. Seal Pressure Gradients: Calculations and Pitfalls. American Association of Petroleum Geologists, AAPG 2014 Annual Convention and Exhibition, Omnipress, Houston, 1834685.

[8] Shaker, S.S. (2005) Geopressure Compartmentalization in Keathley Can You Deep Water, Gulf of Mexico. Comparative Drama, 39, 131-156.

[9] Pan, F.X. (2012) Research of the ERCT Wireline Formation Tester Application. World Well Logging Technology, 2012, 45-48.

[10] Ma, J.G. and Fu, Z.J. (1995) Principles and Applications of Wireline Formation Tester. Petroleum Industry Press, Beijing, 1-174.

[11] Chen, Y.S. and Tan, T.D. (1990) The Pressure Log Reference Manual-Theory and Evaluation of Formation Pressure. Petroleum Industry Press, Beijing, 1-157.

[12] Kuang, L.C. (2005) An Introduction to Applied of the Wireline Formation Data. Petroleum Industry Pressure, Beijing, 1-140. 
[13] Kuang, L.C., Mao, Z.Q., Sun, Z.C., et al. (2003) Reservoir Synthetic Evaluation Based on New Logging Technology. Petroleum Exploration and Development, 30, 58-60.

[14] Course Materials Research Institute (2008) Mathematics (Grade Eight). The Peoples Education Press, Beijing, 38-62.

[15] Wu, Y.J. (2004) Reservoir Geology. Petroleum Industry Press, Beijing, 26-28.

[16] Guo, C., Zhang, J.M., Zhu, J.M., et al. (2016) Fine Characterization of Fluvial Reservoirs under the Condition of Limited Well in Offshore Oilfield: A Case Study from the Sand Body 3-1483 of Kenli3-2 Oilfield. Journal of Northeast Petroleum University, 40, 10-17. 